\title{
The Birth of Exporters: Entry and Scale of Firms in Punjab's Export Sectors
}

\section{Azam Chaudhry", Marjan Nasir ${ }^{* *}$ and Maryiam Haroon ${ }^{* * *}$}

\begin{abstract}
In this paper we analyze which factors affect new firm entry and the scale of new firms in the export clusters of Punjab. Our analysis looks at local conditions (such as the degree of concentration in an industry, the employment of firms of that industry already located in a region, the employment of firms of all industries located in that region) and international conditions (such as the real exchange rates of Pakistan's major trading partners and tariff rates). The results show that more export sector firms will enter highly concentrated industries and that firm entry increases significantly as a result of a depreciation in the trade-weighted real exchange rate, while the impact of changes in trade partner tariffs is not significant.
\end{abstract}

Keywords: Firm, export clusters, entry, Pakistan.

JEL classification: D22, F14.

\section{Introduction}

Though most economists believe that competitiveness is a critical issue both for countries at a macro-level and firms at a micro-level, very few agree on a formal definition of competitiveness. So, competitive firms enter and survive in both domestic and foreign markets, and competitive countries are those that produce goods and services that can survive the test of similar goods and services being produced in foreign countries. But competitiveness is difficult to pin down: According to standard economic theory, firms gain a competitive advantage through lower comparative costs of production by, for example, lower labor costs. However, recent research suggests that nonprice factors are equally important determinants of competitiveness. These factors include human resource endowment, technical factors such as research and development (R\&D) capabilities and the ability to innovate, and managerial and organizational factors (Clark \& Guy, 1998). So, in most cases we know that both firms and countries are

\footnotetext{
* Associate Professor and Dean, Department of Economics, Lahore School of Economics.

** Junior Teaching Fellow, Department of Economics, Lahore School of Economics.

*** Junior Teaching Fellow, Department of Economics, Lahore School of Economics.
} 
competitive if they enter domestic and international markets and survive the resulting competition, but are left trying to figure out why they are competitive (or not competitive) after the fact.

In this article, instead of focusing on what makes sectors competitive, we look at the factors that impact the birth of new firms in the Pakistani export sector. Specifically, we determine which factors affect new firm entry and the scale of new firms in the export clusters of Punjab. What makes this analysis unique is that almost none has been conducted of the factors that affect firm entry in Pakistan. Our analysis looks at local and international conditions: The local conditions include the degree of concentration in an industry, the employment of firms of that industry already located in a region, the employment of firms of all industries located in that region, and the socioeconomic characteristics of that region. The international conditions we look at are the real exchange rates of Pakistan's two major trading partners, the US and EU, together with the tariff rates of the three countries under analysis.

The article is divided into the following sections: Section 2 presents graphical illustrations of the clustering of firms and briefly analyzes entry rates and the scale of entrants among firms of the major exporting clusters in Punjab. Section 3 reviews the literature on firm entry and scale. Section 4 presents our models of entry and scale, and Section 5 gives the results of our estimations. Section 6 provides a discussion of these results, and Section 7 concludes the article.

\section{Mapping Some Key Export Sectors}

Figures 1-6 map the geographical breakdown of some of the major export sector clusters in Pakistan, with new entrants (firms) marked in yellow. The figures illustrate a few important points about the geographic location of export clusters: First, there is a definite clustering of firms in each of these sectors, implying that these firms are benefiting from geographical clustering. These benefits potentially include labor pooling, knowledge spillovers, and specialized inputs. Second, in some of these cases, the clustering is not around just one location but rather multiple locations. This implies that the benefits of geographical clustering of exporters are not limited to one location. Finally, as the figures show, new entrants are definitely entering areas where there are already high concentrations of existing firms.

Tables 1 and 2 show another interesting story about firm entry and scale in the export industries. As Table 1 indicates, firm entry in the export industries is generally low and when one focuses on the textile sector (the 
major export industry), one finds that firm entry here is extremely low, which probably reflects many factors such as competitiveness, barriers to entry, scale of entry, etc. Table 2 shows the scale of new entrants: Here, entrants in the textile sector and cement sector tend to be significantly larger than entrants in other sectors.

Table 3 gives the Herfindahl index of various export industries on the basis of employment, which measures the degree of industry concentration. The index is negatively related to the level of agglomeration, implying that a high value of $H$ is obtained when there are few firms in the industry, while a low value of $H$ is obtained when there are many firms in the industry. As the figures show, the majority of exporting industries have a relatively low level of concentration or, in other words, are relatively less concentrated.

\section{Figure 1: Location of firms in Punjab's textile industry (raw materials)}

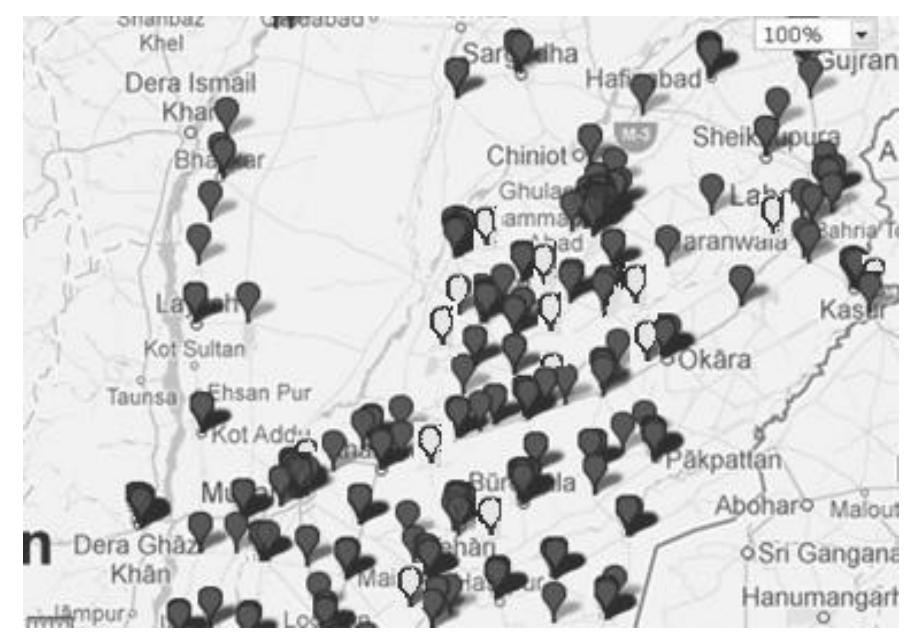


Figure 2: Location of firms in Punjab's textile industry (processed materials)

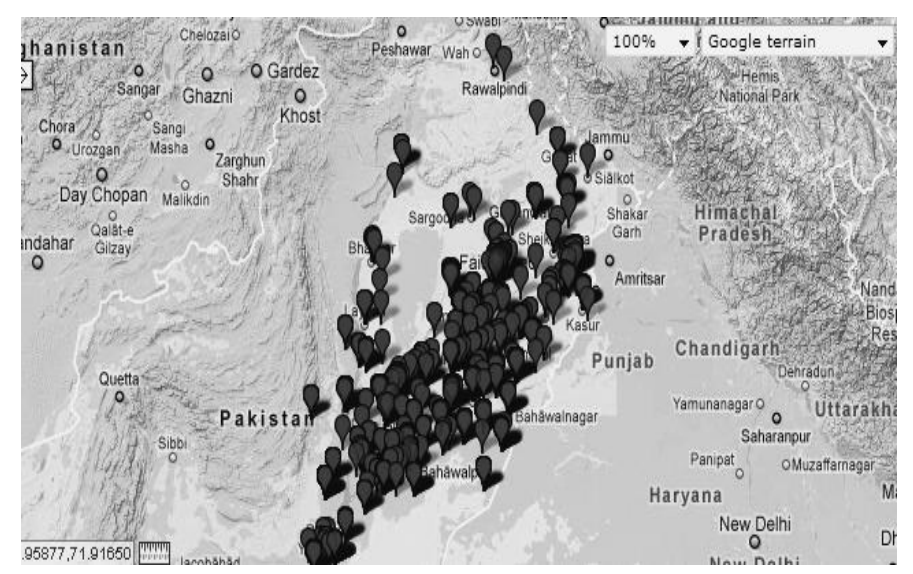

Figure 3: Location of firms in Punjab's textile industry (finished material)

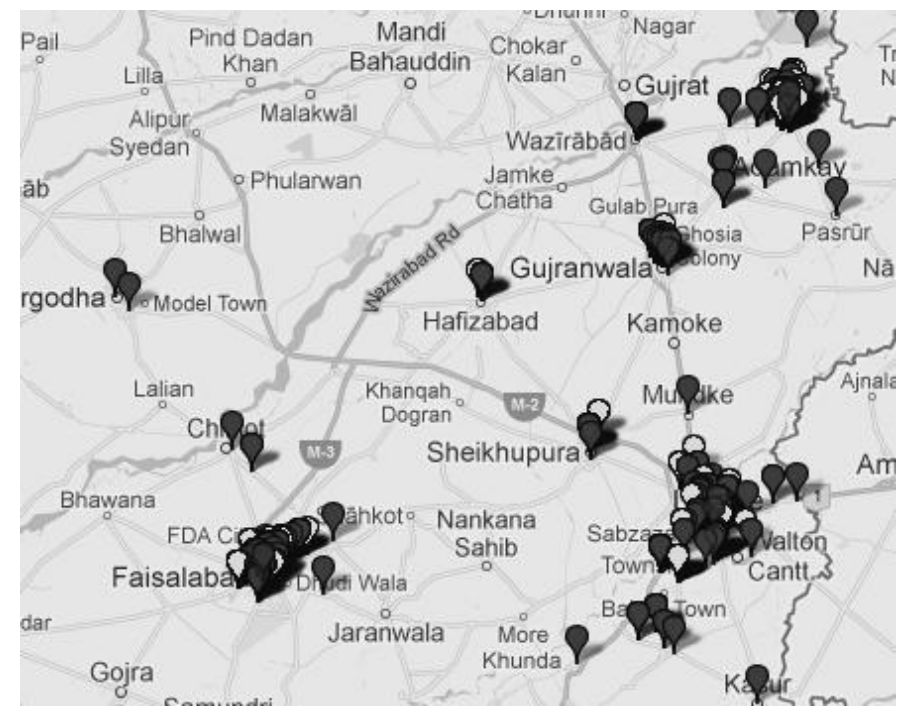


Figure 4: Location of firms in Punjab's sports industry

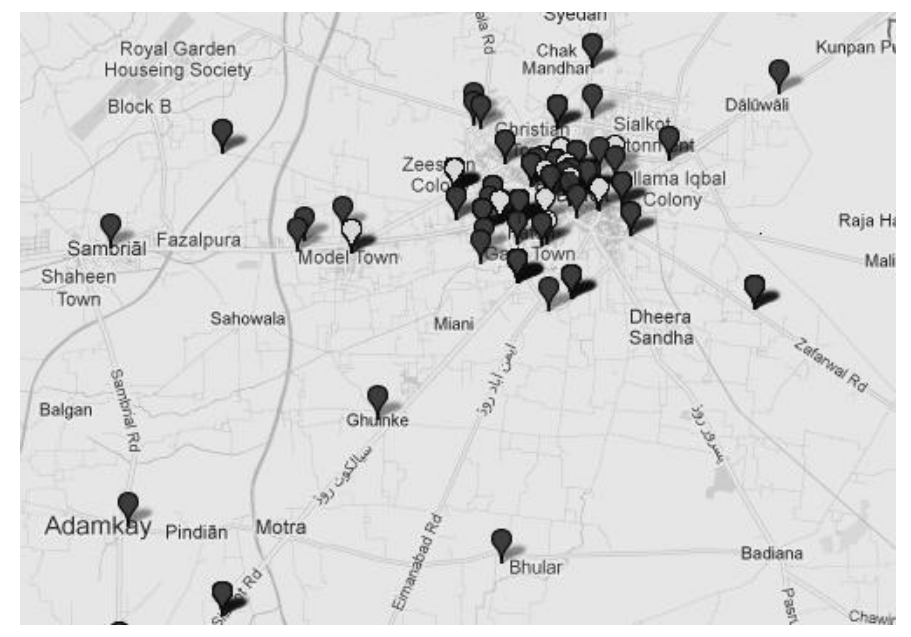

Figure 5: Location of firms in Punjab's carpet industry

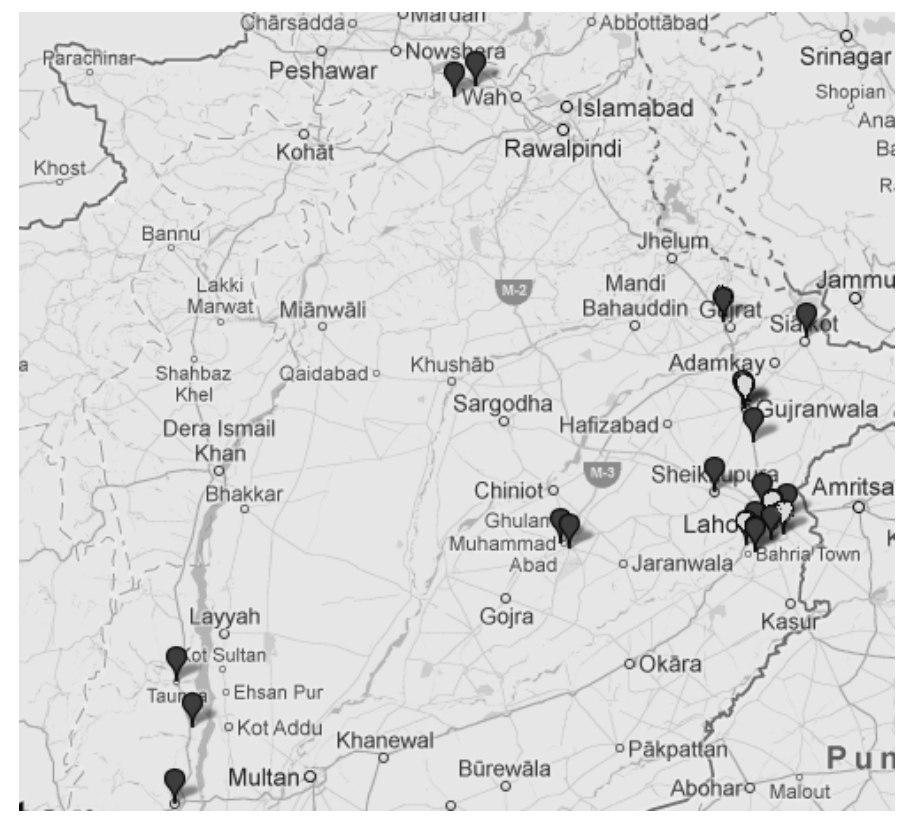


Figure 6: Location of firms in Punjab's leather industry

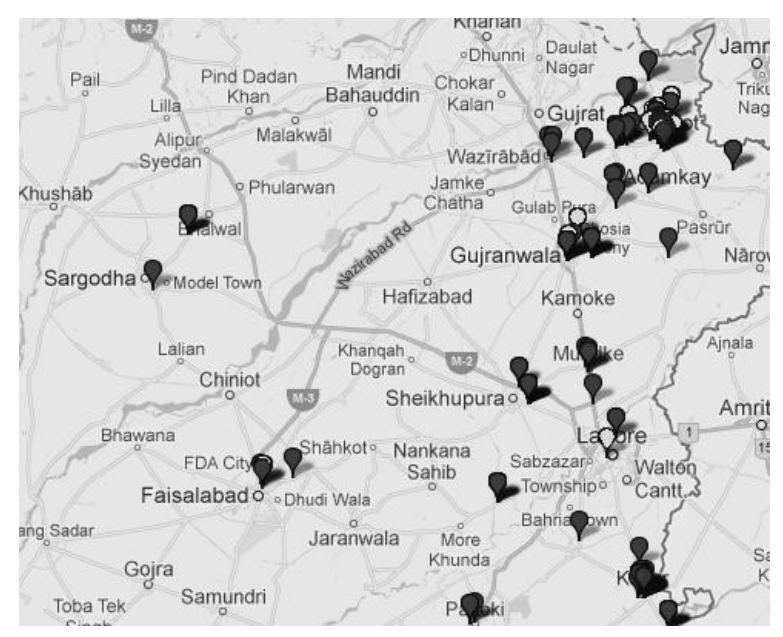


Table 1: Export industries ranked by firm entry, 2010

\begin{tabular}{lc}
\hline Industry & Entry in 2010 \\
\hline Arms and ammunition & 0.200 \\
Beverages & 0.152 \\
Rice & 0.127 \\
Cement & 0.091 \\
Plastic products & 0.087 \\
Chemicals & 0.065 \\
Paper and paper board & 0.055 \\
Vegetable ghee and cooking oil & 0.047 \\
Iron and steel & 0.043 \\
Rubber products & 0.030 \\
Wood products & 0.029 \\
Textiles (processing) & 0.026 \\
Textiles (finished goods) & 0.026 \\
Footwear & 0.026 \\
Sports goods & 0.024 \\
Leather & 0.024 \\
Glass & 0.023 \\
Surgical instruments & 0.022 \\
Baked products and confectionery & 0.007 \\
Textiles (raw material) & 0.002 \\
Carpets and rugs & 0.000 \\
Fruit preservation & 0.000 \\
Photographic goods & 0.000 \\
Spices & 0.000 \\
\hline
\end{tabular}

Note: The entry rate in industry $i$ is equal to the number of new firms in industry $i$ in 2010 that did not exist in $2006\left(N_{i}\right)$ divided by the total number of firms in industry $i$ in $2010\left(I_{i}\right)$. 
Table 2: Export industries ranked by firm scale, 2010

\begin{tabular}{lc}
\hline Industry & Scale in $\mathbf{2 0 1 0}$ \\
\hline Textiles (processing) & 258 \\
Cement & 167 \\
Vegetable ghee and cooking oil & 97 \\
Footwear & 93 \\
Beverages & 90 \\
Textiles (finished goods) & 82 \\
Glass & 72 \\
Photographic goods & 62 \\
Fruit preservation & 58 \\
Paper and paper board & 56 \\
Chemicals & 55 \\
Carpets and rugs & 53 \\
Sports goods & 46 \\
Wood products & 42 \\
Textiles (raw material) & 31 \\
Baked products and confectionery & 27 \\
Arms and ammunition & 25 \\
Leather & 24 \\
Rubber products & 24 \\
Surgical instruments & 21 \\
Rice & 17 \\
Iron and steel & 15 \\
Plastic products & 14 \\
Spices & 10 \\
\hline
\end{tabular}

Note: For the scale of new establishments, we use the employment level of new firms (regarded as arrival in estimation). 
Table 3: Export industries ranked by industrial concentration, 2006

\begin{tabular}{lc}
\hline Industry & Herfindahl index 2006 \\
\hline Spices & 0.5050000000 \\
Wood products & 0.0395782401 \\
Paper and paper board & 0.0086241590 \\
Baked products and confectionery & 0.0064635573 \\
Textiles (processing) & 0.0007092910 \\
Sports goods & 0.0002201743 \\
Textiles (finished goods) & 0.0001751414 \\
Footwear & 0.0000232100 \\
Chemicals & 0.0000108631 \\
Beverages & 0.0000091648 \\
Cement & 0.0000071000 \\
Leather & 0.0000056170 \\
Surgical instruments & 0.0000053057 \\
Glass & 0.0000038827 \\
Textiles (raw material) & 0.0000027374 \\
Rice & 0.0000015475 \\
Vegetable ghee and cooking oil & 0.0000010848 \\
Iron and steel & 0.0000009847 \\
Rubber products & 0.0000007609 \\
Carpets and rugs & 0.0000007199 \\
Plastic products & 0.0000002131 \\
Arms and ammunition & 0.0000000089 \\
Fruit preservation & 0.0000000000 \\
\hline
\end{tabular}

Note: Herfindahl Index $=\Sigma_{k} Z_{k}^{2}$ where $Z_{k}=k^{\text {th }}$ firm's share of industry's employment.

\section{Literature Review}

The literature on firm entry has emphasized the importance of entry rates for regional development. These benefits can either be direct, in the form of job creation, or indirect, such as improvements in supply conditions. Roberts and Thompson (2003) look at how new entrants add to resource flows into their industries by affecting the industry's productivity and contributing to product and technological innovation. They find that these entrants increase competition in the existing market, thus affecting firms' output, pricing, and nonpricing decisions. Caves (1998) shows that the hazard rate of new firms tends to decrease over time, and those that survive initial entry are likely to achieve higher growth rates. 
A number of authors have studied the impact of agglomeration (or firm concentration) on the entry of new firms (Devereux, Griffith, \& Simpson, 2004; Dumais, Ellison, \& Glaeser, 2002; Carlton, 1983; Rosenthal \& Strange, 2007) and their findings suggest that agglomeration has a significant impact on the entry of small firms and low-tech firms. The basic idea behind this relationship is that new establishments or plants are more likely to locate where their input suppliers are located or where other, similar firms or plants exist, which allows new establishments to take advantage of positive externalities in the form of labor pooling or technological or knowledge spillovers.

These effects can vary across industries as well as geographic areas. Porter (2000) puts forward several reasons for why new businesses are more likely to establish within a cluster rather than a remote area. One of these reasons is the presence of lower barriers to entry and exit. Resources such as assets, skills, and inputs are readily available in a cluster, explaining why entry rates are higher in clusters. Similarly, exit rates are also higher due to smaller requirements for specialized investment. The combination of lower entry and exit barriers, together with intense competition from incumbent firms in a cluster, results in high entry and exit rates of firms in more agglomerated industries. However, some studies have found that agglomeration negatively affects new firm entry, as measured by employment share, especially among large firms as they seem to be more fully integrated than small firms.

Recently, authors have divided agglomeration into two parts: localization and urbanization. Localization describes the impact on firms of locating in a specific region within a specific industry; urbanization looks at the benefits accruing to firms by locating near other firms, regardless of the type of industry to which they belong. While knowledge spillovers (see Parr, 2002) and labor pooling are the major benefits to a firm from localization, some of the benefits of urbanization are the presence of diversified suppliers, specialized labor and suppliers, and diversified production (Bosma, Stel \& Suddle, 2006).

Rosenthal and Strange (2007) employ a geographic approach to examine the effect of agglomeration (urbanization and localization) on new firm arrival and the scale of their operation for small, medium, and large establishment levels in the US. They find that urbanization significantly affects arrival and the scale of operation in small establishments in manufacturing industries, while localization affects arrival and the scale of operation in medium establishments within manufacturing industries. Otsuka (2008) performs a similar analysis for new firm formation in Japan, 
and finds that localization and urbanization positively and significantly affect the creation of new firms in the manufacturing industry, but do not lead to new firm formation in the services industry.

Looking beyond local conditions, some researchers have analyzed the effect of international shocks on firm entry and exit. Baggs, Beaulieu, and Fung (2007) find that an appreciation of the currency reduces sales and, hence, the survival of existing firms, while Head and Reis (1997) conclude that a depreciation of the currency tends to increase the number of establishments as well as the scale of production of existing firms. Another branch of the research has looked at the impact of changes in tariffs on firm entry and survival. Head and Reis (1997) find that a decrease in home tariffs leads to an increase in plant closure and a reduction in the scale of production of existing plants in the home country. A reduction in foreign tariffs results in an increase in scale, but does not induce the entry of firms. Gu, Sawchuk, and Whewell (2003) look at firm size and turnover caused by a reduction in tariffs under the free trade agreement (FTA) between the US and Canada, and find that less productive firms exit after tariff reductions.

\section{The Models}

\subsection{Impact of Industrial Concentration and Trade Factors on Firm Entry}

In this section, we present a model of new firm entry similar to that used by other researchers (see Carlton, 1983; Devereux et al., 2004; Dumais et al., 2002). In this model, the entry of new firms in exporting sectors is regressed against industrial concentration and trade variables while controlling for other factors that affect firm entry. Our specific equation looks at the impact of industrial concentration and trade liberalization, following a model used by Baggs et al. (2007), where the entry of new firms in the export sectors is regressed against the real exchange rates of Pakistan's two major trading partners, the US and the EU, together with the tariff rates of the three countries under analysis. Firm-level data is taken on 25 exporting industries for the years 2001-10. The model specification is given below:

$$
\begin{aligned}
\text { Entry }_{i t} & =E_{i t}=\frac{N_{i t}}{I_{i t}}=\beta_{0 i}+\beta_{2} E_{i t}+\beta_{3} \Delta \text { tariff }_{i t}^{P K}+\beta_{4} \Delta \text { tariff }_{i t}^{U S} \\
& +\beta_{5} \Delta \text { tariff }_{i t}^{E U}+\beta_{6} X_{i t}+\tau_{t}+\varepsilon_{i t}
\end{aligned}
$$

$E_{i t}$ is the number of new firms in industry $i$ in year $t\left(N_{i t}\right)$ divided by the number of incumbent firms in industry $i$ in year $t\left(I_{i t}\right) ; E R_{i t}$ is the industry-specific trade-weighted real exchange rate; $\Delta$ tariff $_{i t}$ represents 
changes in Pakistan, US, and EU tariff rates at the industry level; $X$ is the vector of control factors (firm age, firm size, sunk cost, output growth, and concentration ratio); and $\tau$ is the time trend.

The variable measuring entry is calculated for two time periods, i.e., 2001-05 and 2006-10, using the year of establishment as an indicator of the firm being a new establishment in the industry as a fraction of the total number of firms in the industry for that year. To measure the entry rate of new firms, we compare data for two years, e.g., firms that existed in 2006 but not in 2002 are considered new entrants.

The vector of control variables includes other industry factors that impact the entry of firms, such as average firm size in the industry, sunk cost or initial investment by the firm, and output growth of the industry.

In order to measure agglomeration, we use the Herfindahl index, which measures industrial concentration. The index is given below for industry $i$ :

$$
H=\text { Herfindahl index: } \Sigma_{k} Z_{k}^{2}
$$

where $Z_{k}$ is the $k^{\text {th }}$ firm's share of the industry's employment.

The index is also a rough indicator of the industry's market structure. It is negatively related to the agglomeration index, implying that a high value of $H$ is obtained when there are few firms in the industry and will result in lower agglomeration; conversely, a high value of $H$ will be associated with a large number of firms in the industry with higher agglomeration.

The trade-weighted real exchange rate variable ${ }^{1}(E R)$ is constructed using the equation

$$
\text { ExchangeRate }_{i t}=E R_{i t}=\sum_{j \in t o p 2} T W_{i j} \text { rer }_{j t}
$$

where $i$ represents industry, $j$ represents the top two trading partners of the industry (the US and EU in the case of Pakistan), and $t$ represents the time period (2001-10). The trade weight, $T W_{i j}$, is estimated by taking the share of the industry's exports and imports with the trading partners as a proportion of the total exports and imports of all the manufacturing industries exposed

${ }^{1}$ See Baggs et al. (2007, Appendix). 
to trade with the top two trading countries. The other term, rer $_{j t}$, refers to the real exchange rate in terms of the two trading countries, which will be normalized for each country using 2000 as the base year. ${ }^{2}$

Changes in tariff rates for all the years between 2000 and 2010 for each industry in the analysis are taken from World Trade Organization data. Initial investment is used as a proxy for sunk costs and other control variables including industry concentration, averages of firm size, age, and output growth in the industry. We also include time and industry fixed effects.

\subsection{Impact of Local Conditions on Firm Entry and Scale}

In our second analysis we investigate whether industrial agglomeration in a particular district affects firm entry and the scale of exporting industries in Punjab. Specifically, we examine how firm entry and scale in these industries is affected by local environment, which is measured by urbanization, localization, and the socioeconomic indicators of a district. Urbanization is measured by employment in existing establishments within a particular district, while localization is measured using employment in each industry for every district.

We use urbanization to see how the presence of all industries leads to new firm formation in a specific area; we use localization to see how the presence of firms from the same industry leads to new firm formation in a specific area. Our empirical specification follows that of Rosenthal and Strange (2007). The following equations are empirically estimated:

$$
\begin{gathered}
\text { Arrival }_{i d}=A_{i d}=\beta_{0}+\beta_{1} \text { localization }_{i d}+\beta_{2} \text { urbanization }_{d}+ \\
\qquad \beta_{3} X_{d}+\beta_{4 i}+\beta_{5 s p}+\varepsilon_{a, i d} \\
\text { Scaleofoperation }_{i d}=E_{i d}=\alpha_{0}+\alpha_{1} \text { localization }_{i d}+ \\
\alpha_{2} \text { urbanization }_{d}+\alpha_{3} X_{d}+\alpha_{4 i}+\alpha_{5 s p}+\varepsilon_{e, i d}
\end{gathered}
$$

We use 2008 manufacturing industry data from Punjab to calculate firm arrival and scale of operation in the following way. First, we analyze the year of establishment of firms, and calculate firm-level arrivals. Then, we aggregate these firms for each industry and district, giving us arrivals $A_{i d}$ in industry $i$ and district $d$. Those firms that reported their year of establishment as 2008 are regarded as new establishments. For the scale of

\footnotetext{
${ }^{2}$ This is done to avoid the unit problem, which occurs when bilateral exchange rates have different units.
} 
new establishments, we use the employment level of new firms. The two forces of agglomeration are calculated by aggregating activity in a particular industry in a district and total activity in a district for 2006.

In the equation above, $\beta_{4 i}$ and $\alpha_{4 i}$ are industry fixed effects and $X_{d}$ represents the socioeconomic factors of a particular district. Localization includes the employment level of firms in the same industry where arrival occurred within a particular district; urbanization includes the employment level of firms in all industries within a particular district. For our analysis, we also disaggregate localization and urbanization into three levels of establishment: small, medium, and large. Small establishments are limited to firms with fewer than 10 workers, and medium establishments to those with between 10 and 49 workers, while large establishments are characterized as those with 50 or more workers.

Our specification also includes the socioeconomic characteristics of a district, $X_{d}$, such as the average age of the population, percentage of male population, average income, unemployment rate, percentage of population with primary education, percentage of population with secondary education, and percentage of population with more than secondary education. In addition to these variables, we have also incorporated industry fixed effects to account for industry-level characteristics that might affect entry into specific industries, and industry heterogeneity, which may be due to innovation, technological shift-over, new input introduced, etc. Fixed effects at the subprovincial level are also incorporated.

\section{Results}

\subsection{Impact of Industrial Concentration and Trade Factors}

Table 4 presents the results of our analysis on the entry of export sector firms in manufacturing industries in Punjab from 2001 to 2010 as affected by industrial concentration and international factors. In this analysis, the firm entry variable is the ratio of new firms that have entered between time period $t$ and $t-5$ over the total number of firms present in $t$.

The first thing to note is that the impact of agglomeration is positive and significant, showing that more firms will enter highly concentrated industries, holding other industry factors constant. Put more simply, more firms enter less competitive industries.

The results also show that a higher cost of entry does not have an impact on the entry of new firms into the export industries (where high 
cost in this analysis is defined as initial investment or a sunk cost of more than PKR 10 million incurred by firms). This implies that new entrants do not necessarily have to be large investors in their respective sectors.

Another interesting result is that the trade-weighted real exchange rate has a significant impact on firm entry. More specifically, firm entry increases significantly as the result of depreciation in the trade-weighted real exchange rate. The impact of changes in EU and US tariffs is not significant, but this may be because of the lack in variation in these tariff rates.

Table 4: Trade liberalization results for firm entry

\begin{tabular}{ll}
\hline & \multicolumn{1}{c}{ Entry } \\
\hline ER & $-24.205^{* *}$ \\
(Increase $=$ appreciation of PKR) & $(9.5196)$ \\
Tariff PK & 0.002 \\
& $(0.0067)$ \\
Tariff EU & -0.0445 \\
& $(0.0317)$ \\
Tariff US & 0.0002 \\
& $(0.0030)$ \\
Concentration index & $0.119^{* * *}$ \\
& $(0.0401)$ \\
Output growth & 0.005 \\
Firm age & $(0.0341)$ \\
Firm size $=$ small & -0.001 \\
(Dummy $=1$ if $<49$ employees) & $(0.0053)$ \\
Firm size $=$ medium & -0.071 \\
(Dummy $=1$ if $\geq 49$ and $<100$ employees) & $(0.7564)$ \\
Firm size $=$ large & $-0.099^{*}$ \\
(Dummy $=1$ if $\geq 100$ employees) & $(0.052)$ \\
High cost & - \\
(Dummy $=1$ if sunk cost $>$ PKR 10 m) & \\
cons & -0.061 \\
& $(0.1161)$ \\
& $0.566^{* * *}$ \\
& $(0.1664)$ \\
& $\mathrm{N}=48$ \\
& $\mathrm{R}^{2}=0.1838$ \\
\hline
\end{tabular}

Note: ${ }^{* * *}$ denotes statistical significance at the 1 percent level, ${ }^{* *}$ denotes statistical significance at the 5 percent level, and * denotes statistical significance at the 10 percent level. Robust standard errors are given in parentheses. 


\subsection{Impact of Local Conditions on Firm Entry and Scale}

Table 5 shows the impact of local conditions on firm arrivals, using data on local conditions from 2006 and 2004. We have analyzed localization and urbanization both at an aggregated and disaggregated level (where disaggregation is done by establishment size). The aggregated level analysis shows that localization positively and significantly impacts firm arrivals while urbanization has no significant impact. The disaggregated analysis show that localization has a positive and significant impact on arrivals when one focuses on small and large-scale localization (or, in other words, when one looks at the total employment in small- and large-scale firms of the same industry), while urbanization has a positive and significant impact on firm arrival in medium-scale urbanization (or, in other words, when one looks at the employment in all medium firms). These results mean that greater employment in small and large firms from the same industry leads to more new firms entering that area (though the presence of small firms is more attractive to potential new entrants than the presence of large firms). Also, potential new firms are more attracted to districts with more overall employment in medium firms. So, localization and urbanization have a positive impact on firm arrival.

In addition to localization and urbanization, we also look at the impact of district-level socioeconomic characteristics as well as industry fixed effects. The results show that the average income of a district has a positive and significant impact on arrival, which is as expected since higher income in a district implies a higher level of resources available for new entrepreneurs with which to start their own businesses. The results continue to hold when local environment is measured using 2004 data.

The analysis is also carried out for the scale of arrivals, which examines how a district's local conditions affect the scale on which new firms operate. The results are presented in Table 6 . The aggregated analysis shows that localization positively and significantly affects the scale of operation, while the disaggregated analysis shows that localization positively and significantly impacts the scale of arrival when one focuses on small and large firms, though the impact is greater for small firms while urbanization has a positive impact on the scale of operation in medium firms. These results mean that greater employment in small and large firms from the same industry leads to larger firms entering that area (though the presence of small firms is more attractive to potential new entrants than the presence of large firms). Also, potential new firms tend to be larger in districts with more 
employment in medium firms. So, localization and urbanization both have a positive impact on the scale of new firms in an area.

We also carry out the estimations by incorporating local activity for 2004. The results are consistent as they were for 2006, and show that average income has a positive impact on the scale of operation of new firms.

\section{Discussion}

The analysis shows that new firms take advantage of the presence of other firms in their sector (both in terms of the number of entrants and size of new entrants), which makes sense since these firms can benefit from labor pooling, input sharing, and knowledge spillovers from the existing firms. What makes this result more interesting is that these firms benefit both from the existence of small firms in their own sector and from large firms in their own sector. While the importance of small firms can probably be explained by the advantages gained by positive externalities, large firms might be important because they produce sufficiently skilled workers who decide to open their own businesses after gaining experience.

At the same time, new firms also benefit from the presence of medium firms in general (and not just from medium firms in their own sector). This also makes sense since the presence of more firms in general tends to improve the quality of support industries (such as repair and servicing) while also giving rise to a greater number of vertically integrated firms. However, firm entry is hindered (both in terms of the number and the size of new entrants) by the presence of a greater number of large firms in general, which probably reflects entry barriers, higher costs, and possible constraints to the availability of labor and financing.

Finally, higher average income in a geographic area helps new firms (both in terms of the number and size of new entrants), which makes sense since these areas have more entrepreneurs with the means to start their own businesses and also greater access to external financing. 
Table 5: Agglomeration results for firm arrivals

\begin{tabular}{|c|c|c|c|c|c|c|}
\hline & \multicolumn{6}{|c|}{ Arrival } \\
\hline & \multicolumn{3}{|c|}{2006} & \multicolumn{3}{|c|}{2004} \\
\hline & (1) & (2) & (3) & (4) & (5) & (6) \\
\hline Aggregated localization & $3934.236^{* *}$ & & & $38794^{* *}$ & & \\
\hline Localization at small scale & & $194281^{*}$ & $205158^{* *}$ & & $198648^{*}$ & $209833^{* *}$ \\
\hline Localization at medium scale & & 21437 & 13521 & & 20880 & 13098 \\
\hline Localization at large scale & & 3027 & $3659^{*}$ & & 2990 & $3616^{*}$ \\
\hline Aggregated urbanization & -550.459 & -988.607 & & -558.94 & 994.654 & \\
\hline Urbanization at small scale & & & -19384 & & & $-20159^{*}$ \\
\hline Urbanization at medium scale & & & $14634^{*}$ & & & $15188^{*}$ \\
\hline Urbanization at large scale & & & $-3571^{* *}$ & & & $-3644^{* *}$ \\
\hline \multicolumn{7}{|l|}{ Socioeconomic characteristics of a district } \\
\hline Average age of population & 0.01596904 & 0.01085033 & 0.0115291 & 0.01598928 & 0.010627 & 0.010847 \\
\hline Percent male population & -0.0519539 & -0.05499426 & -0.018975 & -0.051476 & -0.05468 & -0.018145 \\
\hline Average income & $0.0002505619^{*}$ & 0.000203447 & $0.0029254^{* *}$ & $0.00025166^{*}$ & 0.00020324 & $0.000298505^{* x}$ \\
\hline Unemployment rate & $0.0002505619^{*}$ & -0.009172229 & $-8.67733 \mathrm{E}-05$ & -0.013586 & -0.009151376 & 0.000418588 \\
\hline Percent pop. with primary education & -0.01832154 & -0.01024366 & -0.0137946 & -0.0183695 & -0.01004939 & -0.013771 \\
\hline Percent pop. with secondary educ. & 0.0019754 & -0.020024 & 0.0076339 & 0.00217344 & -0.020491 & 0.007152 \\
\hline Percent pop. with higher education & -0.002960593 & 0.003375783 & -0.015986 & -0.0029735 & 0.003723236 & -0.01597 \\
\hline Industry fixed effects & Yes & Yes & Yes & Yes & Yes & Yes \\
\hline Sub-provincial regions & Yes & Yes & Yes & Yes & Yes & Yes \\
\hline
\end{tabular}


Table 6: Agglomeration results for scale of operation

\begin{tabular}{|c|c|c|c|c|c|c|}
\hline & \multicolumn{6}{|c|}{ Scale of operation } \\
\hline & \multicolumn{3}{|c|}{2006} & \multicolumn{3}{|c|}{2004} \\
\hline & (1) & (2) & (3) & (4) & (5) & (6) \\
\hline Aggregated localization & $17898^{* *}$ & & & $175579^{* *}$ & & \\
\hline Localization at small scale & & $9430186^{* *}$ & $1.10 \mathrm{e}+07^{* *}$ & & $9646903^{* *}$ & $1.13 \mathrm{e}+07^{* *}$ \\
\hline Localization at medium scale & & 587514 & 294886 & & 559391 & 271627 \\
\hline Localization at large scale & & $150407^{*}$ & $192249^{* *}$ & & $148035^{*}$ & $189612^{* *}$ \\
\hline Aggregated urbanization & -5663 & -22625 & & -5955 & -22886 & \\
\hline Urbanization at small scale & & & $-1024564^{*}$ & & & $-1060941^{*}$ \\
\hline Urbanization at medium scale & & & $768114^{* *}$ & & & $792030^{* *}$ \\
\hline Urbanization at large scale & & & $-156929^{* *}$ & & & $-159869^{* *}$ \\
\hline \multicolumn{7}{|c|}{ Socioeconomic characteristics of a district } \\
\hline Average age of population & 0.724452 & 0.5131922 & 0.5503167 & 0.000722825 & 0.504726 & 0.5146129 \\
\hline Percent male population & -2.447507 & $-2.646506^{*}$ & -0.969514 & -0.002414107 & $-2.62501^{*}$ & -0.928672 \\
\hline Average income & 0.008386 & 0.00591978 & $0.011635^{*}$ & 8.3884E-06 & 0.005880089 & $0.011874^{*}$ \\
\hline Unemployment rate & $-0.89098^{*}$ & -0.7101415 & -0.240239 & $-0.0008899948^{*}$ & -0.7090727 & -0.2163552 \\
\hline Percent pop. with primary educ. & -0.500209 & -0.1530962 & -0.434951 & -0.000498685 & -0.14317 & -0.432097 \\
\hline Percent pop. with secondary educ. & -0.373646 & -1.354276 & 139.046 & -0.000366887 & -1.37588 & 0.126916 \\
\hline Percent pop. with higher educ. & 0.173279 & 0.4668232 & -0.569959 & 0.00017452 & 0.4831995 & -0.563173 \\
\hline Industry fixed effects & Yes & Yes & Yes & Yes & Yes & Yes \\
\hline Sub-provincial regions & Yes & Yes & Yes & Yes & Yes & Yes \\
\hline
\end{tabular}




\section{Conclusions}

The analysis in this paper has shown that more export sector firms will enter highly concentrated industries. The results have also shown that firm entry increases significantly as a result of depreciation in the tradeweighted real exchange rate, while the impact of changes in EU and US tariffs is not significant.

We have also found that greater employment in small and large firms from the same industry leads to more new firms entering that area (though the presence of small firms is more attractive to potential new entrants than the presence of large firms). Also, potential new firms are more attracted to districts with greater overall employment in medium firms. Greater employment in small and large firms from the same industry also leads to larger firms entering that area (though the presence of small firms is more attractive to potential new entrants than the presence of large firms). In this case, potential new firms tend to be larger in districts with more medium firms.

Focusing on district-level characteristics, the results have shown that a district's average income has a positive and significant impact on arrival, which is as expected since higher income in a district implies that there are greater resources available for new entrepreneurs with which to start their own businesses.

From an industrial policy perspective, the results of this analysis imply that the optimal location for new entrants in export industries are the existing clusters for those sectors, but not in areas where there are already a significant number of large industries. Moreover, even though there is an obvious temptation for policymakers to promote industrial development in less-developed regions, higher-income areas are likely to better suit new entrants and existing firms. Finally, while both new and existing firms do benefit from depreciations in the currency, there is insufficient data to say for certain whether they also benefit from reduced tariffs. So, as policymakers look to create new locations to stimulate growth, from the perspective of exporting firms, the old locations are far better. 


\section{References}

Baggs, J., Beaulieu, E., \& Fung, L. (2007). Firm survival, performance, and the exchange rate. Canadian Journal of Economics, 42(2), 393-421.

Bosma, N., Stel, V. A., \& Suddle, K. (2006). The geography of new firm formation: Evidence from independent start-ups and new subsidiaries in the Netherlands (Working Paper, EIM Business and Policy Research). Bedford, UK: Cranfield University School of Management.

Carlton, D. W. (1983). The location and employment choices of new firms: An econometric model with discrete and continuous endogenous variables. Review of Economics and Statistics, 65(3), 440-449.

Caves, R. E. (1998). Industrial organization and new findings on the turnover and mobility of firms. Journal of Economic Literature, 36(4), 1947-1982.

Clark, J., \& Guy, K. (1998). Innovation and competitiveness: A review. Technology Analysis and Strategic Management, 10(3), 363-395.

Devereux, M. P., Griffith, R., \& Simpson, H. (2004). The geographic distribution of production activity in the UK. Regional Science and Urban Economics, 34(5), 533-564.

Dumais, G., Ellison, G., \& Glaeser, E. L. (2002). Geographic concentration as a dynamic process. Review of Economics and Statistics, 84(2), 193-204.

Ellison, G., \& Glaeser, E. L. (1997). Geographic concentration in US manufacturing industries: A dartboard approach. Journal of Political Economy, 105(51), 889-927.

Gu, W., Sawchuk, G., \& Whewell, L. (2003). The effect of tariff reductions on firm size and firm turnover in Canadian manufacturing. Review of World Economics, 139(3), 440-459.

Head, K., \& Reis, J. (1997). Rationalization effects of tariff reductions. Journal of International Economics, 47(2), 295-320.

Otsuka, A. (2008). Determinants of new firm formation in Japan: A comparison of the manufacturing and service sectors. Economic Bulletin, 18(4), 1-7. 
Parr, B. J. (2002). Missing elements in the analysis of agglomeration economies. International Regional Science Review, 25(2), 151-168.

Porter, M. E. (2000). Locations, clusters, and company strategy. In The Oxford handbook of economic geography (pp. 253-274). Oxford, UK: Oxford University Press.

Roberts, B. M., \& Thompson, S. (2003). Entry and exit in a transition economy: The case of Poland. Review of Industrial Organization, 22(3), 225-243.

Rosenthal, S. S., \& Strange, W. C. (2007). Small establishments/big effects: Agglomeration, industrial organization and entrepreneurship. In E. Glaeser (Ed.), The economics of agglomeration. Chicago, IL: University of Chicago Press. 